\title{
Karakter Tokoh Utama Novel Utsukushisa To Kanashimi To Karya Kawabata Yasunari ( Suatu Tinjauan Struktural)
}

\author{
Nurul Fitrah Yani \\ Program Studi Administrasi Bisnis, Politeknik Informatika Nasional LP3I Makassar \\ email: nurulfitrahyani07@gmail.com
}

\begin{abstract}
The aim of the study were one of the approaches in the analysis of literary works (novels) using a structural approach, namely: to find out the main character's character and how the relationship between the main character's character and the flow aspect. The object of this research is the Japanese novel Utsukushisa To Kanashimi To by Kawabata Yasunari, which is translated in Indonesian with the title Beauty and Sorrow by Sobar Hartini. The results of this study indicate that each character in this novel has a varied character. The characters in this novel become the core of the problem which has a strong role in the plot. In each development plot depicts the character's characters through portrayal of the story directly and through conversations between characters.
\end{abstract}

Keywords: Character, Utsukushisa To Kanashimi Novel, Structural

\begin{abstract}
Abstrak
Penelitian ini bertujuan untuk menerapkan salah satu pendekatan dalam analisis karya sastra (novel) dengan menggunakan pendekatan struktural, yaitu : untuk mengetahui karakter tokoh utama dan bagaimana hubungan antara karakter tokoh utama dengan aspek alur. Objek kajian penelitian ini yaitu novel bahasa Jepang yaitu Utsukushisa To Kanashimi To karya Kawabata Yasunari, Yang diterjemahkan dalam bahasa Indonesia dengan judul Keindahan dan Kesedihan Karya Sobar Hartini. Hasil penelitian ini menunjukkan setiap tokoh dalam novel ini memiliki karakter yang bervariasi. Karakter dalam novel ini menjadi inti dari permasalahan yang memiliki peran kuat di dalam alur. Pada setiap perkembangan alur menggambarkan karakter tokoh melalui penggambaran cerita secara langsung dan melalui percakapan antar tokoh.
\end{abstract}

Kata kunci: Karakter, Novel Utsukushisa To Kanashimi , Struktural

\section{Pendahuluan}

Kesusastraan merupakan suatu bagian yang tidak dapat dipisahkan dari kehidupan masyarakat yang berfungsi menyampaikan maksud tertentu kepada masyarakat. Karya sastra dapat juga dikatakan sebagai suatu karya seni yang menghendaki kreativitas yang bersifat imajinatif. (Pradopo, 2007: 34).

Sumardjo, (1997: 3-4) menyatakan bahwa sastra adalah ungkapan pribadi manusia yang berupa pengalaman, pemikiran, perasaan, ide, semangat, keyakinan dalam suatu bentuk gambaran konkret yang membangkitkan pesona dengan alat bahasa. Sehingga sastra memiliki unsur-unsur berupa pikiran, pengalaman, ide, perasaan, semangat, kepercayaan (keyakinan), ekspresi atau ungkapan, bentuk dan bahasa.

Salah satu genre sastra adalah novel. Novel merupakan salah satu jenis kesusastraan yang akan menyajikan suatu pola kehidupan manusia yang diangkat oleh seorang pengarang berdasarkan imajinasinya melalui proses kreativitasnya. Novel merupakan sebuah karya fiksi yang mengungkapkan aspek-aspek kemanusiaan yang lebih mendalam dan disajikan dengan halus (Semi, 1988: 32).

Novel atau sering disebut sebagai roman adalah suatu cerita prosa yang fiktif dalam panjang yang tertentu, yang melukiskan para tokoh, gerak serta adegan nyata yang representatif dalam suatu alur atau suatukeadaan yang agak kacau atau kusut. Novel memunyai ciri bergantung pada tokoh, menyajikan lebih dari satu impresi, menyajikan lebih dari satu efek, menyajikan lebih dari satu emosi (Tarigan, 1991: 164-165). 
Volume 6 Nomor 1

Menurut kaum struktural, karya sastra adalah sebuah totalitas yang dibangun secara koherensif oleh berbagai unsur pembangunnya. Di satu pihak, struktur karya sastra dapat diartikan sebagai susunan, penegasan, dan gambaran semua bahan dan menjadi komponennya yang secara bersama membentuk kebulatan yang indah (Abrams, 1981: 68).

Di pihak lain, struktur karya sastra juga menyarankan pada pengertian hubungan antar unsur (intrinsik) yang bersifat timbal-balik, saling menentukan, saling mempengaruhi, yang secara bersama membentuk satu kesatuan yang utuh (Nurgiyantoro, 2010: 36).

Sastra merupakan karya tulisan indah (belle letters) yang mencatatkan sesuatu dalam bentuk bahasa yang dipadatkan, didalamkan, dibelitkan, dipanjangpendekan dan diputarbalikan, dijadikan ganjil atau cara penggubahan estetis lainnya melalui alat bahasa (Eagleton, 2010: 4).

Apresiasi karya sastra mengandung makna pengenalan melalui perasaaan atau kepekaaan batin, dan pengakuan terhadap nilai-nilai keindahan yang diungkapkan pengarang (Aminuddin, 1987).

Asumsi dasar struktural bahwa sebuah karya merupakan keseluruhan, kesatuan makna bulat, mempunyai koherensi intrinsik, dalam keseluruhan itu setiap bagian dan unsur memainkan peranan, sebaliknya unsur dan bagian mendapat makna seluruhnya dari makna keseluruhan teks (Teeuw, 1982) .

Pandangan lain bahwa analisis struktur dari sebuah karya sastra merupakan prasarana bagi studi manapun juga yang lebih lanjut. Strukturalisme memberikan suatau cara berdisiplin untuk memulai dengan konteks dalam suatu karya sebagai langkah pertama, dan hanya sesudah analisis struktural itu kita bisa melangkah ke luar dari teks ke dunia alamiah atau sosial budaya yang merupakan konteks yang lebih luas (Becker, 1978: 3).

Penggunaan istilah "karakter" (character) sendiri dalam berbagai literatur bahasa Inggris menyarankan pada dua pengertian yang berbeda, yaitu sebagai tokoh-tokoh cerita yang ditampilkan, dan sebagai sikap, ketertarikan, keinginan, emosi dan prinsip moral yang dimiliki tokoh-tokoh tersebut (Stanton, 1965: 17).

Tujuan dari penelitian ini, yaitu mendeskripsikan karakter tokoh utama dalam sebuah karya sastra, yaitu novel Utsukushisa To Kanashimi To karya Kawabata Yasunari

\section{Metode Penelitian}

\section{Jenis Penelitian}

Penelitian ini merupakan penelitian studi kasus dengan analisis deskriptif kualitatif. Penelitian deskriptif ini bertolak pada sebuah realita penggambaran yang terjadi di lapangan, yaitu semua hal yang berkaitan dengan tokoh utama sebagai objek penelitian di dalam novel Utsukushisa To Kanashimi To karya Kawabata Yasunari .

\section{Lokasi dan Waktu}

Penelitian ini dilakukan melalui novel Utsukushisa To Kanashimi To karya Kawabata Yasunari. Penelitian ini berlangsung selama dua bulan, yakni Mei hingga Juni 2011.

\section{Sumber Data}

Sumber data dalam penelitian adalah hasil dari pembacaan novel Utsukushisa To Kanashimi To karya Kawabata Yasunari berupa aksi tokoh dalam mmerakan karakter dalam cerita. 
Volume 6 Nomor 1

\section{Teknik Pengumpulan Data}

Teknik pengumpulan data yang digunakan adalah teknik baca, yaitu membaca dan memahami objek yang terdapat dalam novel, teknik wawancara, yaitu mewawancarai orang yang telah membaca novel tersebut, dan teknik catat, yaitu mencatat hal yang berkaitan dan dianggap penting dalam menganalisis penelitian ini.

\section{Analisis Data}

Analisis dilakukan dengan menganalisis data yang telah terkumpul. Data yang terkumpul dikelompokkan berdasarkan permasalahan yang ada, yang kemudian datadata yang terkumpul diuraikan sebagai suatu analisis. Proses analisis data dimulai dengan menelaah seluruh data yang tersedia dari berbagai sumber, menyusunnya dalam satuan-satuan. Satuan-satuan itu kemudian dikategorisasikan pada langkah berikutnya. Kategori-kategori itu dilakukan sambil membuat koding dan kartu data. Tahap akhir dari analisis data ialah mengadakan pemeriksaan keabsahan data. setelah selesai tahap ini, mulailah kini tahap penafsiran data dalam mengolah hasil sementara.

\section{Hasil dan Pembahasan}

Hasil penelitian menunjukkan bahwa setiap tokoh dalam novel ini memiliki karakter yang bervariasi. Karakter dalam novel ini menjadi pokok/inti dari permasalahan yang memiliki peran kuat di dalam alur. Pada setiap perkembangan alur menggambarkan karakter tokoh melalui penggambaran cerita secara langsung dan melalui percakapan antar tokoh. Persoalan yang dilontarkan pada novel ini pun menjadi persoalan kemanusiaan. Sebagai seorang manusia terutama sebagai generasi muda yang masih gampang terpengaruh dan jatuh cinta dengan orang lain apalagi orang itu sudah berkeluarga. Dalam hidup ini kita dihadapkan pada pilihan yang sulit (karena pada dasarnya hidup ini adalah memilih).

\section{Karakter Tokoh Utama}

Pada bagian ini penulis akan memaparkan karakter ketiga tokoh utama yang terdapat dalam novel "Utsukushisa To Kanashimi To" karya Kawabata Yasunari. Ketiga Tokoh tersebut terdiri dari Otoko, Oki, dan Keiko.

\section{Karakter Tokoh Otoko}

Pada bagian ini, penulis akan memaparkan karakter tokoh Otoko dalam dua bagian. Bagian pertama, dipaparkan mengenai karakter tokoh Otoko di usia muda, dan pada bagian ke dua penulis akan memaparkan mengenai karakter tokoh Otoko di usia dewasa. Pembagian dimaksudkan untuk menghasilkan analisis yang menunjukkan perbandingan dan perubahan karakter yang dimiliki tokoh Otoko ketika masih usia muda dan usia dewasa menjadi dewasa. Berikut adalah gambaran karakter tokoh Otoko.

\section{Karakter Tokoh Otoko Di usia Muda}

Ueno Otoko merupakan seorang gadis yang berumur lima belas tahun. Ia mempunyai seorang adik tiri. Ayahnya meninggal ketika Otoko masih kecil dan ia memutuskan untuk tinggal bersama ibunya. Ayahnya seoarang pebisnis ekspor impor sutra dan wol. Oleh karena itu banyak orang penting yang menghadiri pemakamannya. Hal tersebut dapat dilihat pada kutipan berikut ini:

\section{Data 1:}

"Ayahnya pebisnis ekspor impor sutra dan wol. Banyak orang penting menghadiri pemakamannya, menyumbangkan kemenyan dan pakaian sebagaimana lazimnya," (Hartini, 2005: 93) 
Volume 6 Nomor 1

Di usia mudanya Ueno Otoko digambarkan oleh Kawabata Yasunari sebagai gadis remaja lugu atau polos. Keluguan atau kepolosannya itu tergambar melalui sikapnya yang mau menerima begitu saja cinta seorang pria dewasa yang sudah berkeluarga. Ketika Otoko pasrah begitu saja menerima perlakuan cinta Oki yang merenggut keperawanannya. Hal ini tergambar pada kutipan berikut:

Data 2:

"Oki menghempaskan tubuhnya ke kursi dan meraih Otoko ke pangkuannya, mengangkata dagu supaya memudahkan Otoko. Dia merundukkan tubuh langsingnya pada Oki." (Hartini, 2005: 28)

Kutipan di atas membuktikan bahwa Otoko termasuk orang yang sangat lugu atau polos. Dia rela memberikan keperawannnya begitu saja tanpa pertimbangan apapun. Selain itu, dia juga mudah jatuh cinta kepada orang lain. Hal ini membuktikan karakter Otoko yang yang polos. Dibuktikan melalui kutipan berikut :

Data 3:

"Otoko ingat kata-kata ibunya. Ia bertanya apakah itu terjadi karena masa remajanya dan keluguannya saja sehingga ia merasakan cinta yang seperti itu. Mungkin hal itu menjelaskan nafsu buta yang tidak pernah terpuaskan. Saat ia meregang nikmat dan menggigit bahu pria itu, ia bahkan tidak menyadari bahwa darah kesuciannya telah mengalir." (Hartini,2005 : 154)

Kutipan tersebut menggambarkan sikap Otoko yang pasrah menerima begitu saja perlakuan Oki. Dimana Otoko dibutakan oleh hasrat seksual dan nafsunya dalam bercinta, sehingga Ia rela menerima begitu saja perlakuan cinta dari Oki. Ia menjadi terlena dengan semua itu bahkan, ia tidak menyadari bahwa darah kesuciannya telah mengalir. Hal ini membuktikan karakternya yang lugu. Usianya yang masih belia membuat dirinya menjadi seorang gadis yang lugu yang mudah menerima cinta seseorang.

\section{Karakter Tokoh Otoko Di Usia Dewasa}

Di usia dewasanya Ueno Otoko digambarkan oleh Kawabata Yasunari sebagai seorang wanita yang lebih menunjukkan karakternya sebagai wanita yang dewasa. Dia mununjukkan bahwa dirinya bukan lagi seorang gadis yang lugu dan polos. Seperti yang terdapat pada kutipan berikut:

Data 4:

"Sekarang bersama Keiko, ia bahkan menjadi lebih bebas, ia telah mengembangkan erotisme usia setengah bayanya yang berani dan liar. Mengherankan baginya untuk belajar lewat Keiko sehinggga ia menjadi matang sebagai seorang wanita yang selama bertahuntahun setelah hidup sendirian." ( Hartini, 2005 :158)

Kutipan di atas menunjukkan bahwa diusianya yang sudah dewasa. Otoko tidak lagi menjadi seorang gadis lugu yang mau menerima perlakuan seorang pria begitu saja. Ia mencoba untuk lebih bersikap lebih berani sebagai seorang wanita. Keberaniannya itu ditunjukkan melalui penggambaran kehidupan serta sikap yang diambilnya sebagai tokoh yang bisa belajar dari pengalaman masa lalu. Ia menjadi seorang wanita yang tidak mau terperosok ke dalam lubang yang sama. Ketika Oki datang ke Kyoto untuk menemuinya setelah dua puluh empat tahun berpisah, Otoko tidak langsung menerima kehadirannya untuk bertemu dengan dirinya. Otoko tidak ingin kehadiran Oki membawanya kembali ke masa lalu. Otoko berusaha menjaga jarak dengan Oki. Sikapnya yang selalu menjaga jarak tersebut merupakan sikap dewasa dan bijaksana dari Otoko, walaupun ia menyadari bahwa ia masih mencintai Oki.namun, ia sadar bahwa bila ia tidak menjaga jarak dengan Oki, ada kemungkinan ia akan hanyut dalam perasaan rindunya dan kemudian menginginkan kembali kehadiran Oki dalam hidupnya. Terdapat pada kutipan berikut ini: 
Volume 6 Nomor 1

Data 5:

"Aku akan pulang di Tahun Baru, pagi-pagi aku hanya ingin mendengarkan dentang lonceng bersamamu."

Tak ada jawaban.

"Bisakah aku menghubungimu kembali besok?"

"Tidak, jangan," sahut Otoko agak tergesa-gesa.

Aku akan datang padamu. Jam delapan....barangkali terlalu cepat, bersiap-siaplah sekitar pukul Sembilan di hotelmu. Aku akan memesan kamar di suatu tempat." (Hartini, 2005 : 34)

Kutipan di atas menunjukkan sikap penolakan Otoko terhadap Oki. Hal ini menunjukkan bahwa Otoko lebih bersikap tegas. Dia tidak ingin lagi mengenang masa lalunya bersama Oki. Oleh karena itu, ia berusaha untuk menolak setiap kali Oki ingin bertemu dengannya. Otoko menunjukkan sikap penolakannya dengan mengutus anak muridnya yaitu Keiko sebagai pengganti dirinya menemui Oki. Kawabata Yasunari menunjukkan karakter Otoko yang rendah hati dalam kutipan berikut ini:

Data 6:

"Otoko tak dilihatnya di sekitar lobby. Seorang gadis muda mendekatinya dan bertanya dengan sopan apakah ia tuan Oki. Dia berkata Nona Ueno yang menyuruhnya untuk menemui Oki." (Hartini, 2005 : 38)

Sesuai dengan kutipan tersebut, menunjukkan bahwa Otoko berani mengambil sikap. Terbukti dengan penolakannya pada saat Oki mengatakan bahwa dia akan menghubunginya besok. Akan tetapi Otoko mengatakan jangan. Hal ini menunjukkan sikap penolakannya secara tidak langsung. Walaupun ia sudah mengatan bahwa ia akan menemui Oki. Namun, ia malah tidak datang dan menyuruh nak muridnya yang menemui Oki. Peristiwa tersebut menyatakan bahwa Otoko sudah tidak mau lagi bertemu dengan Oki, meskipun sebenarnya ia masih mencintainya. Sikapnya itu menunjukkan karakternya yang tegas dalam mengambil keputusan, ia betul-betul ingin melupakan Oki. Hal ini dia lakukan karena tidak mau meratapi nasibnya yang menyisakan kisah memilukan. Oleh karena itu, ia berusaha bangkit dengan melupakan masa lalunya. Sikap yang diambil Otoko itu juga dipengaruhi karena sifat kedewasaannya yang menunjukkan karakternya yang tegas.

\section{Karakter Tokoh Oki}

Oki Toshio adalah tokoh yang memiliki peranan penting dalam novel "Utsukushisa To Kanashimi To". Oki yang telah mempunyai seorang istri dan juga anak, menjalin hubungan dengan orang lain yang usianya masih belia. Dalam novel ini digambarkan bahwa Oki adalah seorang pengarang novel terkenal di Jepang.

Di dalam novel secara langsung digambarkan karakter Oki sebagai tokoh playboy yang menyukai gadis-gadis muda. meskipun sudah berkeluarga, ia masih suka berhubungan dengan perempuan lain, terutama dengan perempuan yang masih muda. Bahkan menjelang usia lima puluh lima tahun pun, Oki masih berusaha mendapatkan gadis muda belia. Hal itu terlihat ketika ia berusaha mendapatkan Keiko yang baru berusia dua puluh tahunan. Oki selalu tertarik kepada wanita cantik, ia selalu mengupayakan berbagai cara untuk mendapatkan wanita cantik itu dengan merayunya jatuh ke pelukannya. Ketika Oki berusaha merayu Keiko digambarkan oleh Kawabata Yasunari dalam kutipan berikut ini:

Data 7:

"Kimononya indah sekali. Apakah nona Ueno yang membuat polanya?"

Bukan." Mukanya sedikit memerah."Sebenarnya Kimono yang tampak suram itu menggambarkan kecantikan Keiko sehingga terlihat lebih menonjol." (Hartini, 2005 : 48) 
Volume 6 Nomor 1

Data 8:

"Tuan Oki saya juga manusia."

"Kau sesosok makhluk yang cantik," katanya, membantunya bangkit." (Hartini, 2005 : 106)

Kutipan di atas menggambarkan karakter Oki yang play boy. Hal ini ditunjukkan dengan sikapnya yang lihai dalam menarik perhatian seorang perempuan melalui rayuan manisnya. walaupun dia sudah berkeluarga, tetap saja selalu menjalin hubungan dengan wanita lain, apalagi wanita yang digodanya itu adalah seorang gadis belia yang masih muda. Dibuktikan dengan jalinan asmaranya bersama Otoko dan Keiko. Jelaslah bahwa karakter Oki itu adalah Play boy.

Oki juga memiliki karakter yang tegas, ditandai dengan sikapnya yang suka memutuskan sesuatu secara tiba-tiba. Sikapnya itu ditunjukkan, ketika tiba-tiba ia dirasuki keinginan kuat untuk menemui Otoko di Kyoto. Keinginannya itu mendorong Oki pergi ke Kyoto atas dasar karena cintanya kepada Otoko yang mendalam. Oki sangat mencintai Otoko, Citanya kepada Otoko sangat besar. Meskipun ia tdk bisa menikahi Otoko dengan alasan keluarganya. Sampai pada akhirnya mereka berpisah dalam waktu yang cukup lama. Bayangan Otoko tidak bisa pergi dari kehidupannya. Oleh karena itu, ia memutuskan untuk pergi ke Kyoto menemui Otoko tanpa sepengetahuan istrinya. Alasan dia pergi ke Kyoto bahwa dia ingin mendengar lonceng tahun baru, padahal jauh di dalam hatinya dia ingin sekali bertemu dengan Otoko. Pernyataan tersebut dibuktikan pada kutipan berikut ini:

Data 9:

"Oki datang ke Kyoto untuk mendengar lonceng tahun baru dan bertemu dengan Ueno Otoko, tetapi dia bertanya-tanya alasan manakah yang sebenarnya paling kuat. Tentu saja dia tidak yakin bisa bertemu dengan Otoko. Bisa saja dentang lonceng hanyalah dalih semata, sedang pertemuan dengan perempuan itu adalah kesempatan yang telah lama dinantikannya." (hal 26,13)

Kedatangannya ke Kyoto yang tanpa pikir panjang itu menjadi awal konflik berkepanjangan dalam novel Utsukushisa To Kanashimi To ini. Namun, kedatangannya ke Kyoto untuk menemui Otoko merupakan awal malapetaka yang akan dialaminya. Keputusannya ke Kyoto tanpa berpikir panjang itu, sikapnya yang suka memutuskan sesuatu secara tiba-tiba, menunjukkan karakternya yang tegas. Bila dia ingin melakukan sesuatu atau terbayang akan sesuatu yang dia sukai. Maka, dia akan langsung melakukannya tanpa berpikir panjang atapupun memikirkan orang lain termasuk istrinya sendiri.

\section{Karakter Tokoh Keiko}

Keiko adalah seorang gadis remaja yang tinggal bersama Otoko. Ia jatuh hati kepada Otoko karena melihat karya lukisan Otoko yang menawan. Ia juga merupakan anak yatim piatu. Kedua orang tuanya meninggal sejak ia masih kecil. Walaupun ia memiliki seorang kakak, Ia tidak mau tinggal bersamanya. Ia tidak mau menjadi beban dan menyusahkan kakaknya itu yang sudah berkeluarga. Oleh karena itu, ia memutuskan untuk tinggal bersama Otoko dan menjadi muridnya. Keputusannya itu dilatarbelakangi karena ketertarikannya pada keindahan lukisan dan kecantikan Otoko yang menawan. Ketertarikan Keiko kepada Otoko digambarkan oleh Kawabata Yasunari dalam kutipan berikut ini: 
Volume 6 Nomor 1

Data 10:

"Keiko baru saja lulus dari Sekolah Menengah Atas saat pertama kali datang ke studio Otoko. Ia mengatakan telah melihat semua lukisannya pada sebuah pameran di Tokyo dan melihat fotonya dalam sebuah majalah, dan ia jatuh cinta padanya." (hal 136)

Kutipan di atas menunjukkan ketertarikan Keiko Kepada Otoko. Keiko jatuh cinta kepada Otoko, sejak pertama kali ia melihat foto dan lukisannya. Foto Otoko yang dilihatnya dari awal sudah mengundang ketertarikan kepada Otoko. Sebelumnya telah dipaparkan mengenai kecantikan yang dimiliki oleh Otoko. Oleh karena itulah, Keiko tertarik padanya, ditambah lagi dengan karya lukisannya yang indah membuat orang jatuh hati padanya. Begitu pun dengan Keiko, sejak awal sangat tertarik dengan Otoko. Namun, ketertarikannya itu membawa suatu perasaan yang tidak wajar apa lagi hal tersebut menyebabkan berbagai konflik bagi orang-orang di sekitarnya.

Keiko digambarkan oleh Kawabata Yasunari sebagai seorang pelukis wanita yang mempunyai kecantikan yang luar biasa. Kecantikannya itu membuat para lelaki ingin berkencan dengannya, bahkan lelaki tidak bisa menahan diri karena sosoknya yang begitu menawan dan memancarkan keindahan. Dalam kutipan berikut ini, melalui tokoh Oki, kawabata yasunari menggambarkan kecantikan Keiko:

Data 11:

"Dia memiliki leher yang jenjang dan cuping telinga yang menawan. Semua itu berpadu serasi. Dia memang cantik." (hal 39)

Kutipan di atas menunjukkan bagimana kecantikan yang dimiliki oleh Keiko yang melalui penggambaran fisiknya. Dimana, diceritakan secara langsung tentang kecantikan yang dimilki Keiko. Fisiknya yang cantik itu, digambarkan mengenai lehernya yang jenjang, ia memilki cuping telinga yang cantik. Hal ini membuktikan bahwa Keiko benarbenar merupakan seorang wanita cantik.

Meskipun cantik, Keiko memiliki pribadi yang kadang-kadang menakutkan. Seperti ketika Keiko mencoba merayu Otoko yang sama-sama perempuan. Ketika Keiko menggosokkan obat penghilang bulu di kaki dan di bawah tangannya, Keiko sengaja memperlihatkan kaki dan pahanya kepada Otoko dan menyuruhnya untuk memegangnya. Terdapat pada kutipan berikut ini :

Data 12:

"Saat Keiko datang lagi, ia menyingkap roknya dn mejulurkan kakinya yang putih dan halus seperti susu."

"Sentulah, semua telah putih dan halus sekarang." (Hartini, 2005 : 157)

Kutipan di atas menunjukkan sikap Keiko yang tidak wajar untuk dilakukan seorang wanita kepada sesama wanita. Keiko mencoba untuk menarik perhatian Otoko dengan memperlihatkan keindahan fisik yang dimilkinya. Hal ini ia lakukan agar Otoko tertarik kepadanya. Namun, sama sekali tidak terpengaruh, Otokoh malah merasa meriding dan takut dengan sikap Keiko yang seperti itu. Sikap yang ditunjukkan Keiko menunjukkan karakternya yang janggal/ berbahaya.

Keiko juga merupakan orang yang berbahaya. Kadang sikap yang ia tampilkan susah ditebak. Ia melakukan balas dendam demi Otoko padahal, Otoko sendiri tidak pernah berpikir untuk melakukan balas dendam kepada Oki. Kawabata Yasunari menyebutkan hal itu dalam kutipan berikut ini:

Data 13:

"Tapi demi Tuhan mengapa kamu melakukan itu?"

"Aku ingin menghancurkan keluarganya, membalaskan dendammu." 
Volume 6 Nomor 1

Kutipan di atas membuktikan bahwa Keiko memiliki kepribadian yang menakutkan, dengan menunjukkan karakternya yang antagonis. Keiko yang sejak kecil sudah ditinggal mati kedua orang tuanya, membuat Keiko mandiri. Dalam mengambil keputusan apa pun yang berhubungan dengan dirinya sendiri, ia sendiri yang memutuskannya. Hal ini dibuktikan ketika Keiko mengambil keputusan untuk membalas dendam kepada Oki tanpa adanya persetujuan dengan Otoko. Sikap negatif yang dimiliki Keiko juga digambarkan oleh Kwabata Yasunari pada kutipan berikut ini:

Data 14:

"Empat lima hari setelah Keiko tinggal bersamanya, Otoko menerima surat dari kakak Keiko yang mengatakan bahwa Keiko seorang gadis liar dan keras kepala, bahkan tidak akan mungkin menjadi wanita baik-baik. Tapi ia berharap agar Otoko menerimanya." (hal 139)

Pada kutipan di atas Kawabata Yasunari menyebutkan secara langsung kepada pembaca karakter liar dan keras kepala Keiko. Karena keliaran dan keras kepalanya itu, kadang-kadang Keiko dianggap sebagai orang yang agak kurang waras. Ia tidak pernah merasa pesimis dan selalu menganggap apa yang ia lakukan akan berhasil. Sikap ini menunjukkan bahwa Keiko termasuk orang yang sombong. Ia tidak takut akan dampak yang akan diterimanya atas apa yang telah ia lakukan. Sikapnya yang sombong tersebut digambarkan secara langsung oleh Kawabata Yasunari melalui perkataan dari Otoko dalam kutipan berikut ini:

Data 15:

"Sungguh Keiko. Kamu terlalu sombong, memperolok sedemikian rupa. Kamu akan Kena batunya. Itu bukan sekedar kejahatan berbahaya." (Hartini, 2005 : 84)

Kutipan di atas menunjukkan bahwa dia termasuk orang yang tidak perduli dengan apa yang akan menimpanya. ia selalu yakin atas apa yang ia lakukan tanpa pertimbangan apapun. Ia selalu mengambil suatu tindakan tanpa pertimbangan apapun, tanpa memikirkan perasaan orang lain. Hal ini dapat membuktikan karakternya yang cuek/ egois. Karakter Keiko yang egois, ditunjukkan melalui tindakan dan ucapannya. Ketika ia melakukan sesuatu, tanpa pertimbangan dan selalu mengikuti kata hatinya. Keiko jarang sekali memikirkan masalah moral. yang dipikirkannya adalah bagaimana agar semua keinginannya dapat tercapai. Seperti yang digambarkan Kawabata Yasunari pada kutipan berikut ini :

Data 16:

"Tentu saja semua itu untukmu"!

Otoko mulai merasa adanya tanda bahaya.

"Kumohon kamu jangan lagi pergi ke rumah mereka. Aku tak tahu apa yang bakal terjadi di sana."

"Bukankah kamu sendiri yang ingin, membunuhnya, ketika kamu berada di rumah sakit?"

"Tidak pernah. Aku mungkin punya angan-angan, tetapi untuk membunuh........."

"Kamu membencinya, begitu dalamkah cintamu padanya?"

"karena aku mencintai bayiku."

"Bayi?" Keiko tagu-ragu. "Mungkin aku bisa mendapatkannya darinya."

"Keiko!"

"Kemudian menghancurkannya." ( Hartini, 2005 : 117) 
Kutipan di atas, menunjukkan sikap menunjukkan Keiko yang egois, tidak memikirkan perasaan Otoko sebagai seorang yang pernah kehilangan anaknya dari Oki. Keiko sangat egois, tidak pernah memikirkan orang di sekitarnya.

Sikap keegoannya, ini membuktikan bahwa Keiko memilkiki moral yang sangat lemah, hal itu dikarenakan Keiko sudah tidak memiliki orang tua lagi. Orang tua yang mempunyai peranan dalam membentuk pribadi anak yang moralis, tidak ada dalam kehidupan Keiko. Itulah yang menyebabkan kepribadian Keiko menjadi tidak matang, agresif, dan emosional.

\section{Simpulan}

“Utsukushisa To Kanashimi To ini. Kawabata Yasunari sebagai pengarang mencoba mengeksplorasi cinta melalui perspektif kehidupan dalam sebuah rumah tangga yang diwarnai dengan pengkhianatan. Konflik yang disebabkan karena cinta menjadi permasalahan dalam cerita ini, pencarian jati diri sampai masalah-masalah yang terdapat di dalam novel ini yang seolah-olah memang ada dan terjadi di sekitar kita. Bisa saja kita jadikan sebagai salah satu referensi dalam menyikapi masalah dan penyelesaiannya.

\section{Daftar Pustaka}

Abrams, (1981). Teori Pengantar Fiksi. Yogyakarta: Hanindita.

Aminuddin, 1987. Pengantar Apresiasi Karya Sastra. Bandung: Sinar Baru.

Becker. (1987). Linguistik dan Analisis Sastra, Antologi Stilistika. Jakarta: Pusat. Pembinaan dan Pengembangan Bahasa

Eagleton. (2010). Teori Sastra: Sebuah Pengantar Komprehensif. Yogyakarta: Jala Sutra Nurgiyantoro, Burhan. (2010). Teori Pengkajian Fiksi. Yogyakarta. Gadjah Mada University Press.

Pradopo. Djoko Rachmat. (2007). Prinsip-Prinsip Kritik Sastra. Jogjakarta. UGM Press.

Semi, Atar. (1988). Anatomi Sastra. Padang. Angkasa Raya.

Stanton, Robert. (2007). Teori Fiksi. Yogyakarta. Pustaka Pelajar.

Sumardjo, Jakob. (1970). Kasanah Sastra Dunia. Bandung: Alumni.

Tarigan, Henry Guntur. (1991). Prinsip-Prinsip Dasar Sastra. Bandung: Angkasa. Bandung. Teeuw A. (1982). Khazanah Sastra Indonesia. Jakarta: Balai Pustaka. 